\title{
Chromosomal analysis of Physalaemus kroyeri and Physalaemus cicada (Anura, Leptodactylidae)
}

\author{
Stenio Eder Vittorazzi', Luciana Bolsoni Lourenço', Mirco Solé2, \\ Renato Gomes Faria ${ }^{3}$, Shirlei Maria Recco-Pimentel'
}

I Departamento de Biologia Estrutural e Funcional, Instituto de Biologia, Universidade Estadual de Campinas, 13083-863 Campinas, São Paulo, Brazil 2 Departamento de Ciências Biológicas, Universidade Estadual de Santa Cruz, 45662-000, Ilhéus, Bahia, Brazil 3 Departamento de Biologia, Centro de Ciências Biológicas e da Saúde, Universidade Federal de Sergipe, 49100-000, São Cristóvão, Sergipe, Brazil

Corresponding author: Shirlei Maria Recco-Pimentel (shirlei@unicamp.br)

Academic editor: I. Kuznetcova | Received 25 May 2016 | Accepted 25 June 2016 | Published 8 July 2016

http://zoobank.org/B9B339C5-EB2C-4ED4-BE8E-1E5F1FA0405B

Citation: Vittorazzi SE, Lourenço LB, Solé M, Faria RG, Recco-Pimentel SM (2016) Chromosomal analysis of Physalaemus kroyeri and Physalaemus cicada (Anura, Leptodactylidae). Comparative Cytogenetics 10(2): 311-323. doi: 10.3897/CompCytogen.v10i2.9319

\begin{abstract}
All the species of Physalaemus Fitzinger, 1826 karyotyped up until now have been classified as $2 \mathrm{n}=22$. The species of the $P$. cuvieri group analyzed by C-banding present a block of heterochromatin in the interstitial region of the short arm of pair 5. Physalaemus cicada Bokermann, 1966 has been considered to be a member of the $P$. cuvieri species group, although its interspecific phylogenetic relationships remain unknown. The PcP190 satellite DNA has been mapped on the chromosomes of most of the species of the P. cuvieri group. For two species, P. cicada and P. kroyeri (Reinhardt \& Lütken, 1862), however, only the chromosome number and morphology are known. Given this, the objective of the present study was to analyze the chromosomes of $P$. cicada and $P$. kroyeri, primarily by C-banding and PcP190 mapping. The results indicate that $P$. kroyeri and $P$. cicada have similar karyotypes, which were typical of Physalaemus. In both species, the NORs are located on the long arm of pair 8 , and the C-banding indicated that, among other features, $P$. kroyeri has the interstitial band on chromosome 5, which is however absent in P. cicada. Even so, a number of telomeric bands were observed in P. cicada. The mapping of the PcP190 satellite DNA highlighted areas of the centromeric region of the chromosomes of pair 1 in both species, although in $P$. kroyeri, heteromorphism was also observed in pair 3 . The cytogenetic evidence does not support the inclusion of $P$. cicada in the $P$. cuvieri group. In the case of $P$. kroyeri, the interstitial band on pair 5 is consistent with the existence of a cytogenetic synapomorphy in the P. cuvieri species group.
\end{abstract}

Copyright Stenio Eder Vittorazzi et al. This is an open access article distributed under the terms of the Creative Commons Attribution License (CC BY 4.0), which permits unrestricted use, distribution, and reproduction in any medium, provided the original author and source are credited. 


\section{Keywords}

NOR, C Banding, PcP190 satDNA

\section{Introduction}

The family Leptodactylidae is made up of three subfamilies, the Leptodactylinae, Paratelmatobiinae and Leiuperinae (Pyron and Wiens 2011, Fouquet et al. 2013, Frost 2016). The Leiuperinae include five genera, Edalorhina Jiménez De La Espada, 1870, Engystomops Jiménez De La Espada, 1870, Physalaemus Fitzinger, 1826, Pleurodema Tschudi, 1838 and Pseudopaludicola Miranda-Ribeiro, 1926 (Frost 2016), of which Physalaemus is the most diverse, with 47 species (Frost 2016). Based on the phenetic analysis of morphological data, Nascimento et al. (2005) recognized seven groups of Physalaemus species, the $P$. cuvieri, $P$. signifer, $P$. albifrons, $P$. deimaticus, $P$. gracilis, $P$. henselii and $P$. olfersii groups. However, an alternative approach to the phylogeny of these species, based on the analysis of mitochondrial and nuclear data, produced a new proposal, formed by two major clades, $P$. signifer and $P$. cuvieri. The $P$. cuvieri clade encompasses the $P$. cuvieri, $P$. biligonigerus, $P$. henselii, $P$. gracilis and $P$. olfersii species groups, as well as the species $P$. aguirrei Bokermann, 1966 and $P$. cicada Bokermann, 1966, whose interspecific relationships remain unclear (Lourenço et al. 2015). The $P$. cuvieri group is the largest of the $P$. cuvieri clade, formed by nine described species, $P$. cuvieri Fitzinger, 1826, P. albonotatus (Steindachner, 1864), P. centralis Bokermann, 1962, P. cuqui Lobo, 1993, P. ephippifer (Steindachner, 1864), P. erikae Cruz \& Pimenta, 2004, P. fischeri Boulenger, 1890, P. kroyeri (Reinhardt \& Lütken, 1862) and $P$. albifrons (Spix, 1824). In the analysis of Nascimento et al. (2005), P. cicada was included in the P. cuvieri group, although the phylogenetic analyses of Lourenço et al. (2015) did not confirm this asssignment.

All the Physalaemus species karyotyped up until the present time show $2 \mathrm{n}=22$ (Beçak et al. 1970, Denaro 1972, De Lucca et al. 1974, Silva et al. 1999, Silva et al. 2000, Amaral et al. 2000, Lourenço et al. 2006, Ananias et al. 2007, Tomatis et al. 2009, Milani et al. 2010, Nascimento et al. 2010, Provete et al. 2012, Vittorazzi et al. 2014b). The species of the P. cuvieri group studied by C-banding (Silva et al. 1999, Quinderé et al. 2009, Nascimento et al. 2010, Vittorazzi et al. 2014b) all present a block of interstitial heterochromatin in the metacentric chromosome 5, which is a potential cytogenetic marker of the $P$. cuvieri group (Vittorazzi et al. 2014b, Lourenço et al. 2015).The chromosomal location of the PcP190 satellite DNA is known for $P$. cuvieri, P. centralis, P. albonotatus, P. albifrons and P. ephippifer (Vittorazzi et al. 2011, Vittorazzi et al. 2014a).

For Physalaemus cicada and P. kroyeri, the available cytogenetic data are restricted to the chromosome number and morphology (De Lucca et al. 1974). Given this, the objective of the present study was to evaluate the chromosomal features of these two species, in particular the presence of an interstitial heterochromatic band on chromosome 5, which is recognized as a chromosomal synapomorphy in the P. cuvieri group (Vittorazzi et al. 2014b, Lourenço et al. 2015). 


\section{Material and methods}

\section{Animals}

All the individuals belonging to two species included in our analyses were deposited in the Museum of Zoology "Professor Adão José Cardoso" of the Universidade Estadual de Campinas (ZUEC). The sample of Physalaemus kroyeri consisted of 13 individuals (Males: ZUEC 17480-17484, 17486-17490, 17492 and 17493; Juveniles: 17485) from the municipality of Ilhéus, in Bahia, Brazil (14²47'46.65"S/ 39¹0'19.94"W). For P. cicada, one male specimen (ZUEC 17914) was obtained from Limoeiro, in Pernambuco, Brazil (753'31.90"S/35'27'57.41"W) and 13 specimens (Males: ZUEC 20407-2410, 20415, 20419-20422; Females: 20413 and 20417; Juveniles: 20411, 20418) from Poço Redondo in Sergipe, Brazil (941'13.14"S/ 3741'14.95"W).

The animals were collected with permission of the Instituto Brasileiro do Meio Ambiente e dos Recursos Naturais Renováveis (IBAMA/SISBIO - Process number 10678-2, 20336-1 and 33133-1). For the subsequent techniques, all samples were extracted from euthanized specimens using anesthetic application to the skin (5\% Lidocaine) to minimize animal suffering, according to recommendations of the Herpetological Animal Care and Use Committee (HACC) of the American Society of Ichthyologists and Herpetologists (available in http://www.asih.org), and approved by SISBIO/Institute Chico Mendes de Conservação da Biodiversidade as a condition for the concession license.

\section{Chromosome preparation and staining}

The metaphases were obtained from intestinal cells of the specimens treated with $2 \%$ colchicine for at least 4 hours (following Schmid et al. 2010, or adapted from King and Rofe 1976). The chromosomes were stained with Giemsa (10\%) and then C-banded (King 1980). The slides were then processed using the Ag-NOR method (Howell and Black 1980) or stained with DAPI $(0.5 \mu \mathrm{g} / \mathrm{mL})$ or mithramycin $(0.5 \mathrm{mg} / \mathrm{mL})$. Chromosomal morphometrics were obtained using the MICROMEASURE v3.3 software (Reeves and Tear 2000) and the classification was based on the criteria of Green and Sessions (1991).

\section{Extraction, isolation, cloning and sequencing of the DNA}

The genomic DNA of Physalaemus kroyeri and P. cicada was extracted from samples macerated in TNES buffer (50 mM Tris pH 7.5; $400 \mathrm{mM} \mathrm{NaCl} ; 20 \mathrm{mM}$ EDTA; and $0.5 \%$ SDS), following Medeiros et al. (2013). Samples of the genomic DNA of $P$. cicada and P. kroyeri were submitted to a PCR using the primers P190F (AGA CTG GCT GGG AAT CCC AG) and P190R (AGC TGC TGC GAT CTG ACA AGG) 
(Vittorazzi et al. 2011) for the isolation of the PcP190 satellite DNA. The resulting sequences were purified and ligated to the pGEM-T Easy vector (Promega, Madison, Wisconsin, USA). The recombinant vectors were used to transform $E$. coli bacteria of the JM109 lineage using a TransformAid ${ }^{\mathrm{TM}}$ Bacterial Transformation kit (Fermentas, Burlington, Ontario, Canada), following the maker's recommendations. The procedures for the selection of the recombinant clones and the extraction of the plasmidial DNA were those proposed by Sambrook et al. (1989).

To sequence the fragments, samples of the amplified PCR products were treated with a BigDye Terminator kit (Applied Biosystems, Foster City, California, USA). After precipitation and drying, the products of this reaction were resuspended in loading dye (1:5 Blue-Dextran-EDTA/Formamide), denatured for 3 minutes at $94^{\circ} \mathrm{C}$ and analyzed in an ABI 3730XL automatic sequencer.

All the cloned fragments were sequenced, although for the comparative analyses, only the complete PcP190 sequences were used. It is important to note that the partial units were not noticeably different in their composition from the complete sequences.

\section{Fluorescent in situ Hybridization (FISH)}

The labeling of the isolated PcP190 satellite DNA probes used in this analysis was based on PCR amplification in the presence of Digoxigenin-11-dUTP with a DIG Probe Synthesis PCR (Roche, Pensberg, Bavaria, Germany). The probes were mixed with salmon DNA (1 $\mathrm{ng} / \mu \mathrm{L}$ of probe) and precipitated with ethanol. All the resulting DNA was dissolved in a hybridization buffer at $\mathrm{pH} 7$ composed of deionized formamide (50\%), 2x SSC, phosphate buffer (40 mM), Denhardt's solution, SDS (1\%) and dextran sulfate $(10 \%)$.

The hybridization method used was that described by Viegas-Péquignot (1992), with adaptations for the detection of the Digoxigenin-11-dUTP, which was based on the anti-digoxigenin antibody conjugated with rhodamine (Roche, Pensberg, Bavaria, Germany).

\section{Results}

\section{Physalaemus kroyeri}

The diploid number of Physalaemus kroyeri is $2 \mathrm{n}=22$, with metacentric pairs 1, 2, 5, 6, 9, and 11, submetacentric pairs 4, 7, 8 and 10, and pair 3 being subtelocentric (Figure 1a; Table 1). A secondary constriction was observed on the long arm of pair 8 (Figure 1a), coinciding with the NOR. In the specimens ZUEC 17480, ZUEC 17481 and ZUEC 17483, the NOR was heteromorphic in size (Figure 1b).

Areas of heterochromatin were detected in the centromeric regions of all the chromosomes, in the pericentromeric region of the long arm of the chromosomes of pair 


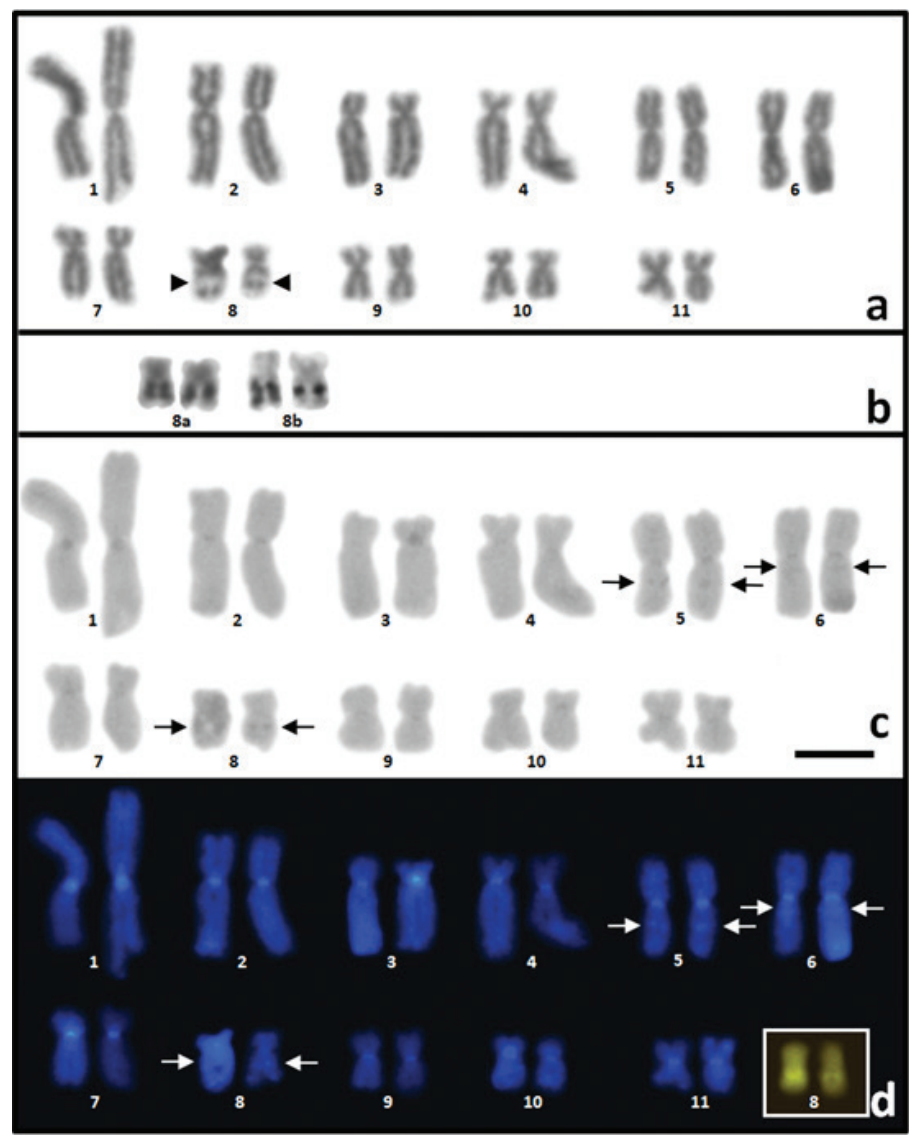

Figure I. a Karyotype of Physalaemus kroyeri stained with Giemsa. The arrowhead indicates the secondary constriction b Pair 8 showing NOR detected by the Ag-NOR method, in the homozygote (8a) and heterozygote (8b) forms $\mathbf{c}$ C-banding stained with Giemsa and d C-banding stained with DAPI. Highlighted in (d), pair 8 stained with mithramycin. In $\mathbf{c}$ and $\mathbf{d}$, the arrows indicate the interstitial heterochromatic bands. Scale bar: $5 \mu \mathrm{m}$.

Table I. Morphometry of the karyotypes of Physalaemus kroyeri and Physalaemus cicada. NC: number of the chromosome; CI: centromeric index; AR: arm ratio; CC: chromosomal classification (Green and Session 1991). A total of 10 karyotypes were analyzed in each species.

\begin{tabular}{c|c|c|c|c|c|c|c|c|c|c|c}
\hline \multicolumn{10}{c}{ P. kroyeri } \\
\hline NC & 1 & 2 & 3 & 4 & 5 & 6 & 7 & 8 & 9 & 10 & 11 \\
\hline CI & 0.45 & 0.39 & 0.24 & 0.26 & 0.47 & 0.44 & 0.32 & 0.32 & 0.42 & 0.34 & 0.42 \\
\hline AR & 1.15 & 1.5 & 3.11 & 2.8 & 1.11 & 1.22 & 2.09 & 2.01 & 1.33 & 1.94 & 1.34 \\
\hline CC & M & M & ST & SM & M & M & SM & SM & M & SM & M \\
\hline \multicolumn{10}{|c|}{ cicada } \\
\hline NC & 1 & 2 & 3 & 4 & 5 & 6 & 7 & 8 & 9 & 10 & 11 \\
\hline CI & 0.45 & 0.39 & 0.23 & 0.27 & 0.44 & 0.43 & 0.3 & 0.29 & 0.42 & 0.37 & 0.4 \\
\hline AR & 1.19 & 1.51 & 3.13 & 2.8 & 1.23 & 1.27 & 2.28 & 2.43 & 1.37 & 1.62 & 1.48 \\
\hline CC & M & M & ST & SM & M & M & SM & SM & M & M & M \\
\hline
\end{tabular}


6 , adjacent to the NOR of the chromosomes of pair 8 , and interstitially on one of the arms of the metacentric chromosomes of pair 5 (Figure 1c,d). While pair 5 is metacentric, the interstitial $\mathrm{C}$ band is located on the arm that appears to be slightly larger. It was also possible to observe a positive mithramycin band together with the NOR (Figure 1d).

\section{Physalaemus cicada}

Physalaemus cicada has a diploid number of $2 \mathrm{n}=22$, with metacentric pairs 1, 2, 5, 6, 9, 10 and 11, submetacentric pairs 4, 7 and 8, and one subtelocentric pair, pair 3 (Figure 2a; Table 1). A large secondary constriction can be observed on the long arm of pair 8 , together with the NOR (Figure 2a, inset).

Regions of constitutive heterochromatin were detected in the centromeres of all the chromosomes, in the proximal region of the long arm of the chromosomes of pair 2 , in the pericentromeric region of the long arm of the chromosomes of pair 4, in the telomeric regions of both arms of the chromosomes of pairs 1, 2, 5, 6 and 7, and a similar pattern, but restricted to the long arms of pairs 3, 4, 9, 10 and 11 (Figure 2b,c). A large block of heterochromatin can be observed on the long arm of pair 8 (Figure $2 \mathrm{~b}$ ), coinciding with the NOR which was also strongly stained by mithramycin in Cbanded metaphases (Figure 2c - inset). When C-banding was followed by DAPI staining, all the centromeric and telomeric $\mathrm{C}$-bands were revealed as well as a band adjacent to the NOR (Figure 2).

\section{PcP190 satellite DNA}

After cloning, sequencing, and the search for similar sequences using the BLASTn tool in GenBank, it was possible to conclude that the sequences obtained with the primers P190F and P190R belong to the PcP190 satellite DNA family, which was first identified in Physalaemus cuvieri (Vittorazzi et al. 2011).

It was possible to clone three fragments of the PcP190 satellite DNA of Physalaemus kroyeri, all of which contain a complete repeat unit of this satellite DNA, of 190 bps (Figure 3). The mean similarity between these fragments was $95 \%$, and when compared with the PcP190 sequences of P. cuvieri (Vittorazzi et al. 2011), the similarity was 93\%. Five complete sequences of the PcP190 were obtained from $P$. cicada, of which, one was 189 bps in length, two were 192 bps long, and two were 200 bps. These differences in the size of the $P$. cicada result from a polymorphic region of $20 \mathrm{bps}$, characterized by substitutions and indels (Figure 3). The mean similarity of the $P$. cicada sequences was $88 \%$, decreasing to $78 \%$ in comparison with $P$. cuvieri (Vittorazzi et al. 2011). The sequences obtained for $P$. kroyeri and $P$. cicada were $79 \%$ similar, on average.

In the karyotype of Physalaemus kroyeri, the PcP190 satellite DNA was detected in the centromeric region of pair 1 . In two of the three individuals analyzed, in addition, 


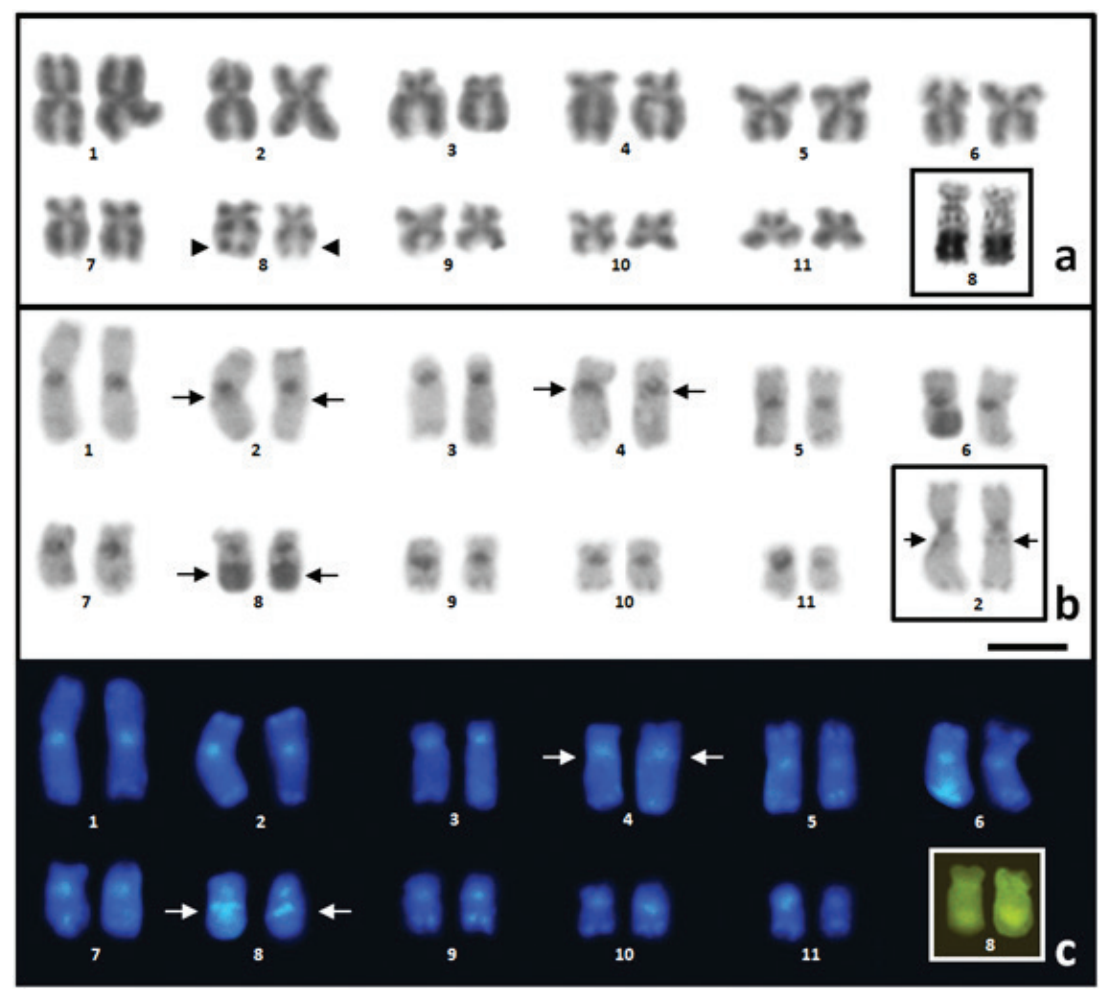

Figure 2. a Karyotype of Physalaemus cicada stained with Giemsa. The arrowhead indicates the secondary constriction in pair 8 , highlighting the NOR in pair $8 \mathbf{~ b ~ C - b a n d i n g ~ o f ~ t h e ~ k a r y o t y p e , ~ h i g h l i g h t i n g ~}$ the proximal $\mathrm{C}$ band in pair 2 c C-banding followed by DAPI staining, highlighting pair 8 stained with mithramycin. In $\mathbf{b}$ and $\mathbf{c}$, the arrows indicate the interstitial and pericentromeric heterochromatic bands. Scale bar: $5 \mu \mathrm{m}$.

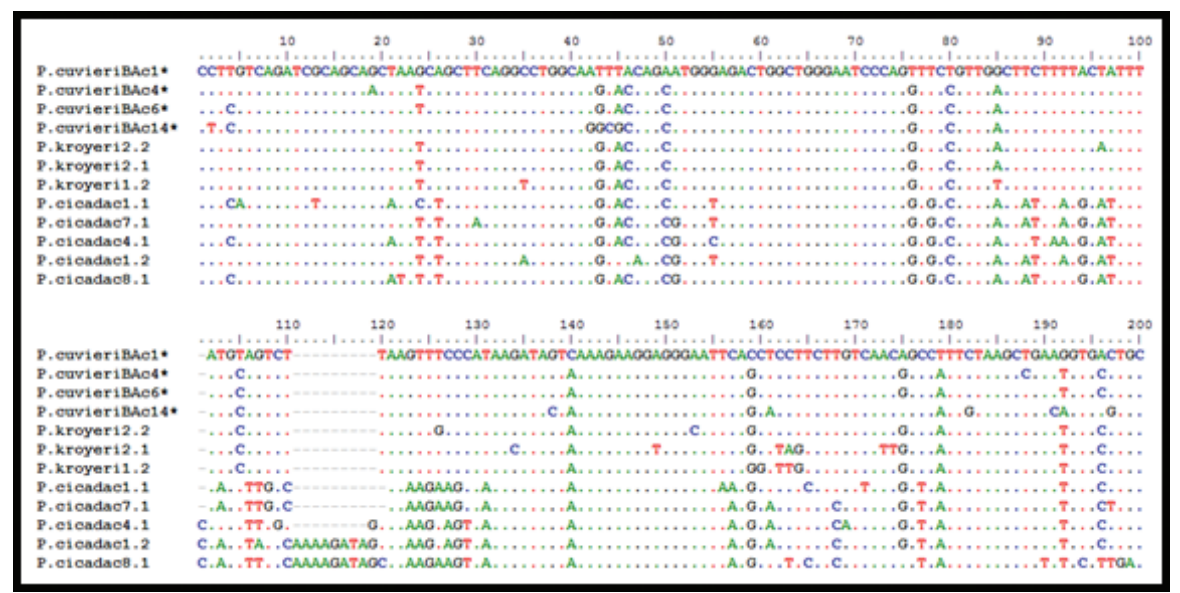

Figure 3. Alignment of the PcP190 satellite DNA sequences of the species Physalaemus kroyeri, Physalaemus cicada and P. cuvieri available in GenBank* (JF281121, JF281117, JF281109 and JF281124). 


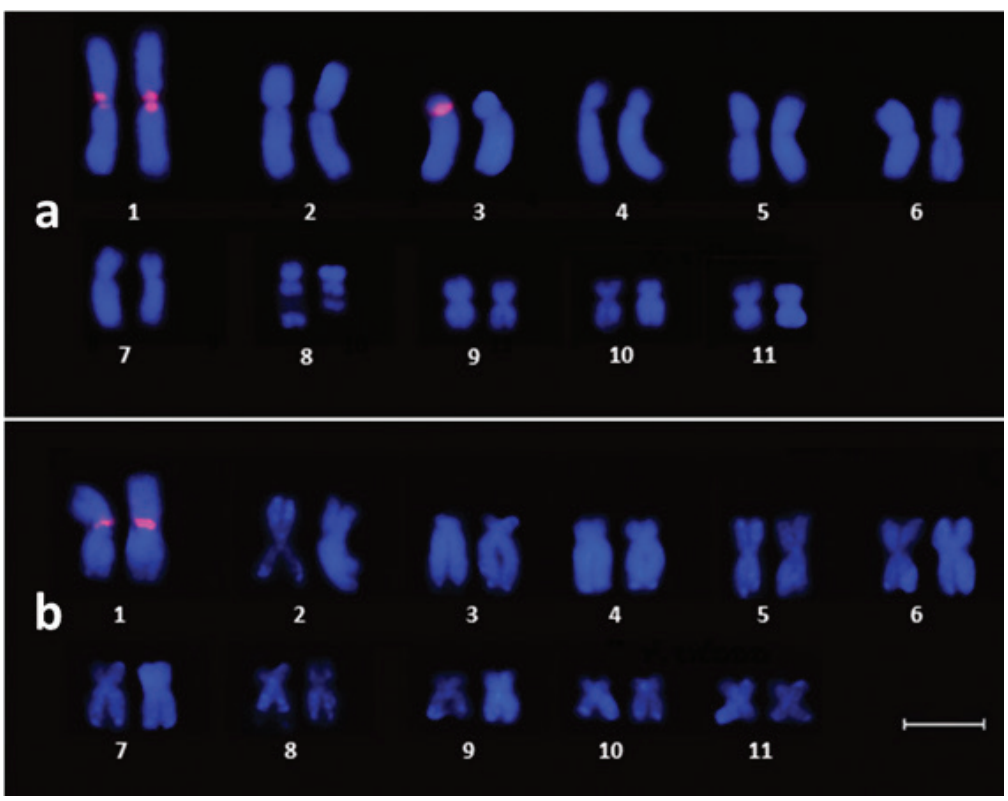

Figure 4. Karyotype of a Physalaemus kroyeri and b Physalaemus cicada hybridized with PcP190 satellite DNA probes. Note the signs of hybridization of the probe in the centromeric region of pair 1 in (a) and (b), and in one of the chromosomes of pair 3 in (a). Scale bar: $5 \mu \mathrm{m}$.

the PcP190 was also detected in the centromeric region of one of the chromosomes of pair 3 (Figure 4a). In P. cicada, the PcP190 was detected in the centromeric region of pair 1 , in the individuals from both Limoeiro and Poço Redondo (Figure 4b).

\section{Discussion}

The number and morphology of the chromosomes observed in the karyotypes of Physalaemus kroyeri and P. cicada were the same as those found by De Lucca et al. (1974). The fundamental number (FN) of these karyotypes is 44, which is characteristic of most of the Physalaemus species for which cytogenetic data are available, such as P. cuvieri (Beçak et al. 1970, Silva et al. 1999, Quinderé et al. 2009), P. soaresi Izecksohn, 1965 (De Lucca et al. 1974), P. marmoratus (Reinhardt \& Lütken, 1862) (Beçak et al. 1970, Amaral et al. 2000), P. biligonigerus (Cope, 1861) (Amaral et al. 2000, Silva et al. 2000), P. henselii (Peters, 1872), P. riograndensis Milstead, 1960 (Tomatis et al. 2009), P. olfersii (Lichtenstein \& Martens, 1856) (De Lucca et al. 1974; Silva et al. 2000, Milani et al. 2011), P. ephippifer (Nascimento et al. 2010), P. barrioi Bokermann, 1967 (Provete et al. 2012), P. albifrons, P. centralis (Denaro 1972, Vittorazzi et al. 2014b), P. albonotatus, P. cuqui, and P. santafecinus Barrio, 1965 (Vittorazzi et al. 2014b). However, the species of the P. signifer clade and P. fernandezae (Muller, 1926) 
(part of the $P$. henselii group of the $P$. cuvieri clade) (see Lourenço et al. 2015) have $\mathrm{FN}=42$, due to the presence of a telocentric pair classified as pair 11 .

Comparing the karyotypes of Physalaemus kroyeri and P. cicada with one another and the karyotypes described for other Physalaemus species, it is possible to infer homologies in the first seven pairs of chromosomes. This is because the morphology of pairs 1-7 is highly similar in the karyotypes analyzed, despite some differences in size (e.g., P. albonotatus in Vittorazzi et al. 2014b). Even so, it is possible that some of these inferences are erroneous, given that some pairs of chromosomes (pairs 3 and 4, for example, and 5 and 6) are very similar. On the other hand, the recognition of homologies in pairs 8 to 11 is hampered by the fact that these chromosomes are all very small and similar in morphology, except for the telocentric chromosomes classified as pair 11 in the species of the $P$. signifer clade and $P$. fernandezae (see Lourenço et al. 2015 and references therein).

In the karyotype of Physalaemus kroyeri, the NOR is located interstitially on the long arm of the chromosomes of pair 8, a situation also observed in $P$. albifrons (Vittorazzi et al. 2014b), which are sister species inferred by Lourenço et al. (2015), and in some populations of P. cuvieri (Quinderé et al. 2009). The results of the present study permit the differentiation of the karyotypes of $P$. albifrons and $P$. kroyeri by the presence of interstitial bands of heterochromatin on the long arms of pairs 6 and 8 in P. kroyeri, which are absent in P. albifrons (Vittorazzi et al. 2014b), and an interstitial band on the short arm of pair 8 in $P$. albifrons, which was absent in $P$. kroyeri. One other difference between the two species can be observed in pair 1 , in which PcP190 satellite DNA is present in P. kroyeri, but not in P. albifrons (Vittorazzi et al. 2014a).

The interstitial $\mathrm{C}$ band in the metacentric pair 5 is present in all the species of the Physalaemus cuvieri group karyotyped up until now, which Vittorazzi et al. (2014b) proposed as a potential cytogenetic marker for the $P$. cuvieri group, confirmed by the phylogenetic analysis of Lourenço et al. (2015). The results of the present study also indicate that the marker is present in $P$. kroyeri, another species of the $P$. cuvieri group.

While the chromosome pair 5 of Physalaemus kroyeri is classified morphologically as metacentric, the arm on which the interstitial band is located is slightly larger, which calls into question the $5 \mathrm{p}$ position of this band in the other species of the $P$. cuvieri group. This difference may have resulted from some structural modification of the chromosome, such as a pericentric inversion, amplification of part of this arm, or a deletion on the opposite arm. Whatever the case, the difference in the position of this interstitial band does not alter its status as a chromosomal synapomorphy in the $P$. cuvieri group.

The absence of this interstitial band of heterochromatin on chromosome 5 in the karyotype of Physalaemus cicada, keeps the interpecific relationships of this species in doubt. While $P$. cicada has been considered to be a member of the $P$. cuvieri group, based on its morphological similarities (Lynch 1970, Nascimento et al. 2005), Lourenço et al. (2015) found no support for this arrangement in their phylogenetic analyses. 


\section{PcP190 satellite DNA}

It was possible to recognize PcP190 satellite DNA in both Physalaemus kroyeri and $P$. cicada, as found in a number of other Physalaemus species, such as P. cuvieri, P. centralis, $P$. albonotatus, $P$. albifrons, P. ephippifer, P. marmoratus and $P$. nattereri (Steindachner, 1863), as well as members of other leptodactylid genera, such as Pleurodema diplolister (Peters, 1870), Leptodactylus latrans (Steffen, 1815) and Crossodactylus gaudichaudii Duméril \& Bibron, 1841 (Vittorazzi et al. 2014a) and in the hylid genus Pseudis (Gatto et al. 2016). This sequence is well conserved, and appears to have an ancient origin in the anurans (Vittorazzi et al. 2014a, Gatto et al. 2016).

In Physalaemus cicada, both the sequences and the location of the PcP190 in the karyotype provide interesting insights into the comparison of this species with those of the P. cuvieri group. On average, the PcP190 of the species of this group are $90 \%$ similar to one another (Vittorazzi et al. 2014a), although this falls to $78 \%$ in the comparison with $P$. cicada. The chromosomal mapping of these sequences in P. cicada is also distinct from that of the P. cuvieri group, given the lack of a PcP190 site in pair 3 , which is characteristic of all the species of the P. cuvieri group analyzed to date (Vittorazzi et al. 2011, 2014a). These differences may reflect a more distant phylogenetic relationship between $P$. cicada and the species of the $P$. cuvieri group. However, we must consider that given family of satellite DNA may present a different number of repetitions, even in closely-related species, given that the evolutionary dynamics of these sequences favors their continuous amplification and deletion in the genome. This is covered in the original proposal for a DNA satellite library (Fry and Salser 1977, Meštrović et al. 1998), which indicated that different families of satellite DNA coexist in a genome, but that new families may arise continually through the restructuring of the distribution and quantity of the older sequences.

\section{Conclusion}

The interstitial heterochromatic band on the metacentric chromosome 5, considered to be a cytogenetic synapomorphy of the Physalaemus cuvieri species group was found in P. kroyeri. In contrast, this marker was absent in P. cicada, which did not support the inclusion of $P$. cicada in the $P$. cuvieri species group.

\section{Contribution of the authors}

SEV developed the study, collected $P$. kroyeri and P. cicada, ran the analyses and drafted the manuscript. MS collected P. kroyeri and RGF collected P. cicada, both these authors revised the manuscript. SMRP and LBL developed and coordinated the study and revised the manuscript. 


\section{Acknowledgments}

We are grateful to Daniel Pacheco Bruschi for helping collect P. cicada from Limoeiro. We thank the Coordenação de Aperfeiçoamento de Pessoal de Nível Superior (CAPES-PROAP), the Fundação de Amparo a Pesquisa do Estado de São Paulo (FAPESP, 2010/11300-7), and the Conselho Nacional de Desenvolvimento Científico e Tecnológico (CNPq, 620163/2008-9) for financial support. We also thank the Instituto Brasileiro do Meio Ambiente e dos Recursos Naturais Renováveis and the Secretaria de Estado do Meio Ambiente e Recursos Hídricos de Sergipe for permission to collect specimens.

\section{References}

Amaral MJLV, Cardoso AJ, Recco-Pimentel SM (2000) Cytogenetic analysis of three Physalaemus species (Amphibia, Anura). Caryologia 53: 283-288. doi: 10.1080/00087114.2000.10589207

Ananias F, Bombeiro AL, Silva CDB, Silva APZ, Haddad CFB (2007) Cytogenetics of Eupemphix nattereri Steindachner, 1863 (Anura: Leiuperidae) and karyotypic similarity with species of related genera: taxonomic implications. Acta Zoologica Sinica 53: 285-293.

Beçak ML, Denaro L, Beçak W (1970) Polyploidy and mechanisms of karyotypic diversification in Amphibia. Cytogenetics 9: 225-238. doi: 10.1159/000130093

DeLuccaEJ,Jim J, Foresti F (1974) Chromosomal studies in twelve species of Leptodactylidae and one Brachycephalidae. Caryologia 27: 183-191. doi: 10.1080/00087114.1974.10796573

Denaro L (1972) Karyotypes of Leptodactylidae Anurans. Journal of Herpetology 6: 71-74. doi: $10.2307 / 1563095$

Frost DR (2016) Amphibians species of the world: an online reference. Version 6.0 (15 march 2016). American Museum of Natural History, New York. http://research.amnh.org/herpetology/amphibia/index.html

Fry K, Salser W (1977) Nucleotide sequences of HS- $\alpha$ satellite DNA from kangaroo rat Dipodomys ordii and characterization of similar sequences in other rodents. Cell 12: 1069-1084. doi: 10.1016/0092-8674(77)90170-2

Fouquet A, Blotto BL, Maronna MM, Verdade VK, Juncá FA, de Sá R, Rodrigues MT (2013) Unexpected phylogenetic positions of the genera Rupirana and Crossodactylodes reveal insights into the biogeography and reproductive evolution of leptodactylid frogs. Molecular Phylogenetics and Evolution 67: 445-457. doi: 10.1016/j.ympev.2013.02.009

Gatto KP, Busin CS, Lourenço LB (2016) Unraveling the sex chromosome heteromorphism of the paradoxical frog Pseudis tocantins. PLoS ONE 11(5): e0156176. doi: 10.1371/journal. pone. 0156176

Green DM, Sessions SK (1991) Nomenclature for Chromosomes. In: Amphibian cytogenetics and evolution. Academic Press, San Diego, 431-432. doi: 10.1016/b978-0-12-297880-7.50021-4

Howell WM, Black DA (1980) Controlled silver staining of nucleolus organizer regions with a protective colloidal developer: a 1-step method. Experientia 36: 1014-1015. doi: 10.1007/ BF01953855 
King M (1980) C-banding studies on Australian hylid frogs: secondary constriction structure and the concept of euchromatin transformation. Chromosoma 80: 191-217. doi: 10.1007/BF00286300

King M, Rofe R (1976) Karyotypic variation in the Australian gekko Phyllodactylus marmoratus (Gray) (Gekkonidae: Reptilia). Chromosoma 54: 75-87. doi: 10.1007/BF00331835

Lourenço LB, Nascimento JAA, Andrade GV, Rossa-Feres DC, Recco-Pimentel SM (2006) Chromosomal analyses of the leptodactylids Pleurodema diplolistris and Physalaemus nattereri (Amphibia, Anura). Amphibia-Reptilia 27: 481-489. doi: 10.1163/156853806778877103 Lourenço LB, Targueta CP, Baldo D, Nascimento J, Garcia PCA, Andrade GV, Haddad CFB, Recco-Pimentel SM (2015) Phylogeny of frogs from the genus Physalaemus (Anura, Leptodactylidae) inferred from mitochondrial and nuclear gene sequences. Molecular Phylogenetics and Evolution 92: 204-216. doi: 10.1016/j.ympev.2015.06.011

Lynch JD (1970) Systematic status of the American leptodactylid frog genera Engystomops, Eupemphix, and Physalaemus. Copeia 1970: 488-496. doi: 10.2307/1442276

Medeiros LR, Lourenço LB, Rossa-Feres DC, Lima AP, Andrade GV, Giaretta A, Egito GTB, Recco-Pimentel SM (2013) Comparative cytogenetic analysis of some species of the Dendropsophus microcephalus group (Anura, Hylidae) in the light of phylogenetic inferences. BMC Genetics 14: 29. doi: 10.1186/1471-2156-14-59

Meštrović N, Plohl M, Mravinac B, Ugarković ĐĐ (1998) Evolution of satellite DNAs from the genus Palorus - experimental evidence for the 'library' hypothesis. Molecular and Biology Evolution 15: 1062-1068. doi: 10.1093/oxfordjournals.molbev.a026005

Milani M, Cassini CS, Recco-Pimentel SM, Lourenço LB (2010) Karyotypic data detect interpopulational variation in Physalaemus olfersii and the first case of a supernumerary chromosome in the genus. Animal Biology Journal 2: 21-28. doi: 10.1655/HERPETOLOGICAD-12-00020

Nascimento J, Quinderé YRSD, Recco-Pimentel SM, Lima JRF, Lourenço LB (2010) Heteromorphic Z and W sex chromosomes in Physalaemus ephippifer (Steindachner,1864) (Anura, Leiuperidae). Genetica 138: 1127-1132. doi: 10.1007/s10709-010-9501-9

Nascimento LB, Caramaschi U, Cruz CAG (2005) Taxonomic review of the species groups of the genus Physalaemus Fitzinger, 1826 with revalidation of the genera Engystomops Jiménez-de-La-Espada, 1872 and Eupemphix Steindachner, 1863 (Amphibia, Anura, Leptodactylidae). Arquivos do Museu Nacional Rio de Janeiro 63: 297-320.

Provete DB, Garey MV, Toledo LF, Nascimento J, Lourenço LB, Rossa-Feres DC, Haddad CFB (2012) Redescription of Physalaemus barrioi (Anura: Leiuperidae). Copeia 2012: 507-518. doi: 10.1643/CH-10-142

Pyron RA, Wiens JJ (2011) A large-scale phylogeny of Amphibia including over 2,800 species, and a revised classification of extant frogs, salamanders, and caecilians. Molecular Phylogenetics and Evolution 61: 543-583. doi: 10.1016/j.ympev.2011.06.012

Quinderé YRD, Lourenço LB, Andrade GV, Tomatis C, Baldo D, Recco-Pimentel SM (2009) Polytypic and polymorphic NOR variations in the widespread anuran Physalaemus cuvieri (Anura, Leiuperidae). Biological Research 42: 79-92. doi: 10.4067/S0716-97602009000100008 Reeves A, Tear J (2000) MicroMeasure for Windows, version 3.3. Free program distributed by the authors over the Internet from http://www.colostate.edu/Depts/Biology/MicroMeasure. 
Sambrook J, Fritsch EF, Maniatis T (1989) Molecular Cloning - A Laboratory Manual. Cold Spring Harbor Laboratory Press, Cold Spring Harbor.

Schmid M, Bogart JP, Hedges SB (2010) The chromosomes of terraranan frogs. Insights into vertebrate cytogenetics. Cytogenetic and Genome Research 130-131: 1-568. doi: 10.1159/000301339

Silva APZ, Baldissera-Jr FA, Haddad CFB, Kasahara S (2000) Karyotypes and nucleolus organizer regions of the genus Physalaemus (Anura, Leptodactylidae). Iheringia, Série Zoológica 88: 159-164.

Silva APZ, Haddad CFB, Kasahara S (1999) Nucleolus organizer regions in Physalaemus cuvieri (Anura, Leptodactylidae), with evidence of a unique case of Ag-NOR variability. Hereditas 131: 135-141. doi: 10.1111/j.1601-5223.1999.00135.x

Tomatis CG, Baldo D, Kolenc F, Borteiro C (2009) Chromosomal variation in the species of the Physalaemus henselii group (Anura, Leiuperidae). Journal of Herpetology 43: 555-560. doi: 10.1670/08-122R1.1

Viegas-Pequignot (1992) In situ hybridization to chromosomes with biotinylated probes. In: Willernson D (Ed.) In situ hybridization: a practical approach. Oxford University Press-IRL Press, Oxford, 137-158.

Vittorazzi SE, Lourenço LB, Del-Grande ML, Recco-Pimentel SM (2011) Satellite DNA derived from $5 \mathrm{~S}$ rDNA in Physalaemus cuvieri (Anura, Leiuperidae). Cytogenetic and Genome Research 134: 101-107. doi: 10.1159/000325540

Vittorazzi SE, Lourenço LB, Recco-Pimentel SM (2014a) Long-time evolution and highly dynamic satellite DNA in leptodactylid and hylodid frogs. BMC Genetics 15: 111. doi: 10.1186/s12863-014-0111-x

Vittorazzi SE, Quinderé YRSD, Recco-Pimentel SM, Tomatis C, Baldo D, Lima JRF, Ferro JM, Lima JD, Lourenço LB (2014b) Comparative cytogenetics of Physalaemus albifrons and Physalaemus cuvieri species groups (Anura, Leptodactylidae). Comparative Cytogenetics 8: 103-123. doi: 10.3897/CompCytogen.v8i2.6414 